\title{
Carbon Sources for Yeast Growth as a Precondition of Hydrogen Peroxide Induced Hormetic Phenotype
}

\author{
Ruslana Vasylkovska, Natalia Petriv, and Halyna Semchyshyn \\ Department of Biochemistry and Biotechnology, Vasyl Stefanyk Precarpathian National University, 57 Shevchenko Street, \\ Ivano-Frankivsk 76018, Ukraine \\ Correspondence should be addressed to Halyna Semchyshyn; semchyshyn@pu.if.ua
}

Received 30 September 2015; Accepted 10 December 2015

Academic Editor: Susana Merino

Copyright (C) 2015 Ruslana Vasylkovska et al. This is an open access article distributed under the Creative Commons Attribution License, which permits unrestricted use, distribution, and reproduction in any medium, provided the original work is properly cited.

\begin{abstract}
Hormesis is a phenomenon of particular interest in biology, medicine, pharmacology, and toxicology. In this study, we investigated the relationship between $\mathrm{H}_{2} \mathrm{O}_{2}$-induced hormetic response in S. cerevisiae and carbon sources in yeast growth medium. In general, our data indicate that (i) hydrogen peroxide induces hormesis in a concentration-dependent manner; (ii) the effect of hydrogen peroxide on yeast reproductive ability depends on the type of carbon substrate in growth medium; and (iii) metabolic and growth rates as well as catalase activity play an important role in $\mathrm{H}_{2} \mathrm{O}_{2}$-induced hormetic response in yeast.
\end{abstract}

\section{Introduction}

Hormesis has been observed in a variety of organisms: from bacteria to humans, responding to a wide range of chemical, physical, and biological stressors [1-3]. According to the hormesis theory, low doses of stress-inducing factors lead to stimulatory hormesis response and improvement of biological functions, whereas at high doses the deleterious effects prevail [4]. Hormesis may activate defense pathways ensuring protection against higher doses of the same agent ("preadaptation") as well as other specific stressors ("crossprotection") [5-7]. Therefore, hormetic response suggests the existence of complex mechanisms that sense and respond to a variety of stress-inducing factors. In addition, the specificity of stress response is determined by physiological state of an organism that, in turn, depends on the accessibility of specific carbon/energy sources.

Recent studies strongly support the notion that hydrogen peroxide plays a crucial role in the induction of hormesis $[7,8]$. On the other hand, its effect can be considered as harmful, because at high concentrations $\mathrm{H}_{2} \mathrm{O}_{2}$ causes oxidative damage to cell structures [9]. Manipulation of reproductive potential through different carbon sources for yeast cultivation as well as hormesis-stimulating concentrations of hydrogen peroxide appears to be an effective approach to improve yeast survival and cross-adaptation to different kinds of stress.

In the present work, we used Saccharomyces cerevisiae grown on fermentable and nonfermentable substrates to study the effect of different concentrations of hydrogen peroxide on yeast reproductive ability and potential role of the primary antioxidant enzymes such as superoxide dismutase (SOD) and catalase in $\mathrm{H}_{2} \mathrm{O}_{2}$-induced hormetic response.

\section{Materials and Methods}

The Saccharomyces cerevisiae strain used in this study was

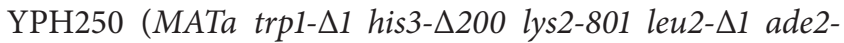
101 ura3-52) described earlier [10], and kindly provided by Professor Inoue (Kyoto University, Japan). Chemicals were obtained from Sigma-Aldrich Chemical Co. (USA) and Fluka (Germany). All chemicals were of analytical grade.

Yeast cells were grown with shaking at 175 r.p.m. and $28^{\circ} \mathrm{C}$ in Erlenmeyer flasks containing YPD liquid medium ( $1 \%$ yeast extract, $2 \%$ peptone, and $2 \%$ glucose) in a volume that respected the ratio 1:5 regarding media volume to flask volume. Glucose was substituted for fructose $(2 \%)$, ethanol $(1 \%)$, or glycerol $(1 \%)$ in the respective experiments. 
For experiments, overnight cultures were diluted to about $10^{6}$ cells $/ \mathrm{mL}$ in respective medium. Aliquots of the experimental cultures after $24 \mathrm{~h}$ growth were exposed to different concentrations of hydrogen peroxide, followed by their incubation at $28^{\circ} \mathrm{C}$ for $1 \mathrm{~h}$ [11]. Control cells were incubated under the same conditions but without hydrogen peroxide. After incubation, cells from experimental or control cultures were used for the reproductive ability evaluation.

Yeast reproductive ability was analyzed by plating in triplicate on YPD agar after proper dilution. The plates were incubated at $28^{\circ} \mathrm{C}$ for 3 days and the colony forming units (CFU) counted [12]. Reproductive ability was expressed as percentage of total amount of cells plating on YPD agar.

Cell growth was measured as an increase in optical density at $590 \mathrm{~nm}\left(\mathrm{OD}_{590}\right)$ with a spectrophotometer "Labsystems Multiskan MCC 1340" (Finland). The growth rate was counted as a change in $\mathrm{OD}_{590}$ per hour during the exponential phase.

Yeast cells from respective cultures were collected by centrifugation at room temperature $(5 \mathrm{~min}, 8000 \mathrm{~g})$ and washed with $50 \mathrm{mM}$ potassium phosphate (K-phosphate) buffer $(\mathrm{pH}$ 7.0). The yeast pellets were resuspended in lysis buffer $(50 \mathrm{mM}$ K-phosphate buffer, $1 \mathrm{mM}$ phenylmethylsulfonyl chloride, and $0.5 \mathrm{mM}$ EDTA). Cell extracts were prepared by vortexing yeast suspensions with glass beads $(0.5 \mathrm{~mm})$ as described earlier [11] and kept on ice for immediate use.

The following parameters were measured spectrophotometrically with a Spekol 211 spectrophotometer (Carl Zeiss, Germany), a SF-46 spectrophotometer (LOMO, USSR), and “Labsystems Multiskan MCC 1340" (Finland). To evaluate the metabolic activity of yeast cells 2,3,5-triphenyltetrazolium chloride was used. Metabolically active cells are capable of reducing the dye to water-insoluble red formazan that can be extracted from the cells with an ethanol/acetone mixture, and the absorbance of this solution was then read at $485 \mathrm{~nm}$ [12]. The results are expressed as $\mathrm{OD}_{485}$ units per $10^{8}$ cells.

The content of carbonyl groups in proteins was measured by determining the amount of 2,4-dinitrophenylhydrazone formed upon reaction with 2,4-dinitrophenylhydrazine [13]. The carbonyl content was calculated from the absorbance maximum of 2,4-dinitrophenylhydrazone measured at $370 \mathrm{~nm}$ using an extinction coefficient of $22 \mathrm{mM}^{-1} \mathrm{~cm}^{-1}$. The results are expressed in nanomoles per milligram of protein.

The activity of SOD was assayed at $406 \mathrm{~nm}$ as the inhibition of quercetin oxidation by superoxide-anion-radical [11]. One unit of SOD activity was defined as the amount of soluble protein of supernatant that inhibited the maximal rate of quercetin oxidation by $50 \%$.

Catalase activity was determined by monitoring the disappearance of hydrogen peroxide at $240 \mathrm{~nm}$ using the extinction coefficient for hydrogen peroxide of $39.4 \mathrm{M}^{-1} \mathrm{~cm}^{-1}$ [11]. One unit of catalase activity was defined as the amount of supernatant protein that utilized $1 \mu \mathrm{mol}$ of substrate per minute. The enzyme activities were measured at $25^{\circ} \mathrm{C}$ and expressed per milligram of soluble protein in supernatant.

To evaluate the total antioxidant capacity of yeast cells colored 2,2'-azinobis-(3-ethylbenzothiazoline-6-sulfonic acid) radical cation $\left(\mathrm{ABTS}^{\circ+}\right)$ was used [14]. The $\mathrm{ABTS}^{\circ+}$ was decolorized by antioxidants according to their concentrations and antioxidant capacities. This change in color was measured as a change in $\mathrm{OD}_{420}$ with trolox as the standard. The parameter is expressed in nmol of trolox equivalents per milligram of soluble protein in supernatant.

Protein concentration was determined by the Coomassie brilliant blue G-250 dye-binding method [15] with bovine serum albumin as the standard. Experimental data are expressed as the mean value of 3-10 independent experiments \pm the standard error of the mean (SEM), and statistical analysis was performed using variance (ANOVA) followed by a Student-Newman-Keuls test.

\section{Results}

3.1. $\mathrm{H}_{2} \mathrm{O}_{2}$-Induced Hormetic Response Depends on the Type of Carbon Source for Yeast Growth. According to recent studies hydrogen peroxide plays a crucial role in the induction of hormesis $[7,8]$ and effect of hydrogen peroxide depends on the type of monosaccharide in yeast cultivation medium [16]. Figure 1 demonstrates the influence of different concentrations of hydrogen peroxide on the reproductive ability of yeast cells grown on fermentable (glucose or fructose) and nonfermentable (glycerol or ethanol) carbon sources. Although in all cases we observe typical biphasic concentration-response curve, exhibiting hormetic effect of hydrogen peroxide, $\mathrm{H}_{2} \mathrm{O}_{2}$ triggers the hormetic response at different concentrations.

Yeast grown on glucose demonstrated the peak hormetic response at $0.15 \mathrm{mM} \mathrm{H}_{2} \mathrm{O}_{2}$ (Figure $1(\mathrm{a})$ ), whereas in fructosegrown cells the peak was seen after their incubation with as high as $7.5 \mathrm{mM} \mathrm{H}_{2} \mathrm{O}_{2}$ (Figure $1(\mathrm{~b})$ ). At the hormetic concentrations of hydrogen peroxide, yeast grown in glucoseand fructose-containing medium showed $151 \%$ and $170 \%$ of the initial reproductive ability (without $\mathrm{H}_{2} \mathrm{O}_{2}$ ), respectively. Independently of the type of monosaccharide in the cultivation medium, yeast demonstrated the lowest reproductive ability at the highest $\mathrm{H}_{2} \mathrm{O}_{2}$ concentration used $(100 \mathrm{mM})$, but fructose-grown cells comparing to glucose-grown cells showed higher colony growth $(\sim 74 \%$ and $\sim 55 \%$ of the initial reproductive ability, resp.).

The peak hormetic response of glycerol-grown cells was seen at $0.05-0.15 \mathrm{mM} \mathrm{H}_{2} \mathrm{O}_{2}$ (157-177\% of the control reproductive ability). In contrast to a sharp rise of the reproductive activity at hormetic concentrations of $\mathrm{H}_{2} \mathrm{O}_{2}$ in cells grown on both monosaccharides and glycerol, ethanol-cultivated yeast (Figure 1(d)) had a broad peak hormetic response at $0.05-$ $10.0 \mathrm{mM} \mathrm{H}_{2} \mathrm{O}_{2}$ (147-180\% of the initial reproductive ability). However, $100 \mathrm{mM} \mathrm{H}_{2} \mathrm{O}_{2}$ reduced proliferative activity of ethanol-grown yeast to $60 \%$ of the initial value, whereas at $100 \mathrm{mM} \mathrm{H} \mathrm{O}_{2}$ glycerol-grown cells demonstrated colony growth similar to the control one.

Thus carbon substrate in cultivation medium is an important factor that determines yeast response to hydrogen peroxide.

3.2. Carbon Source Affects the Growth Rate of Yeast Culture. Next we studied yeast growth on glucose, fructose, glycerol, and ethanol that seem to be associated with different hormetic phenotypes described above. As seen in 


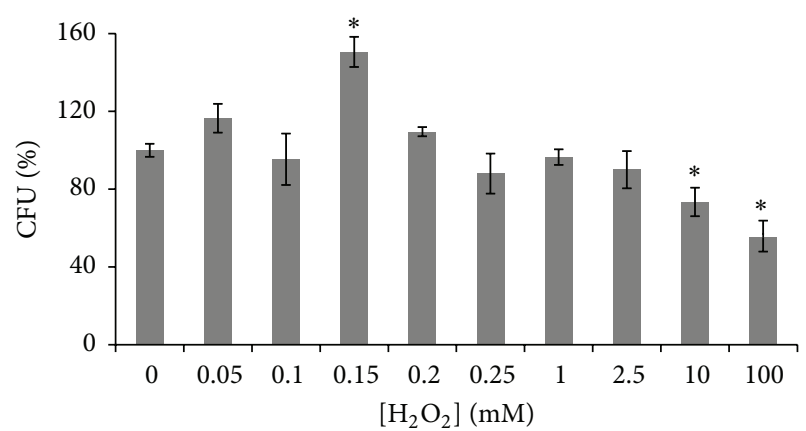

(a)

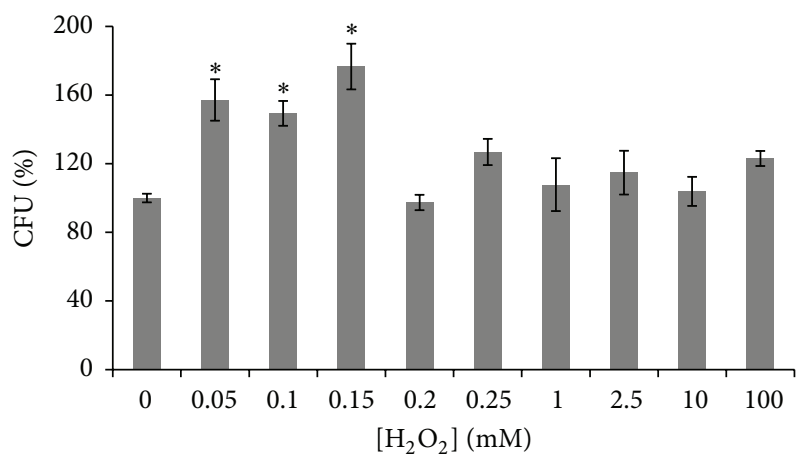

(c)

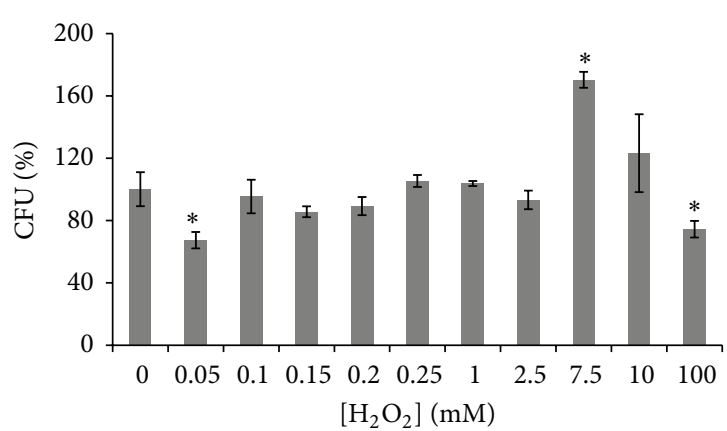

(b)

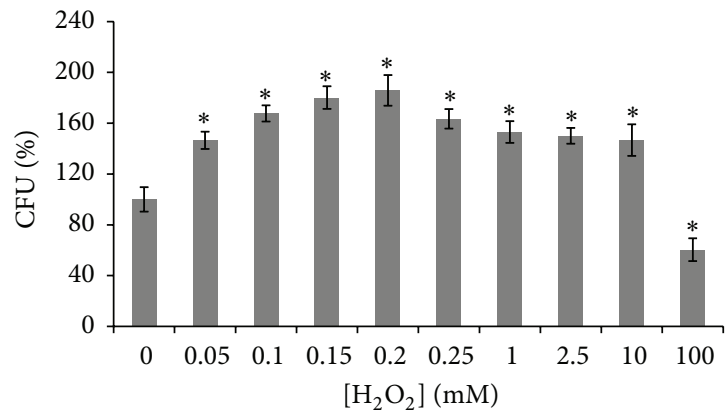

(d)

FIGURE 1: Effect of hydrogen peroxide on reproductive ability of $S$. cerevisiae growing on glucose (a), fructose (b), glycerol (c), and ethanol (d). Results are shown as the mean \pm SEM $(n=3-10)$. ${ }^{*}$ Significantly different from control (without $\mathrm{H}_{2} \mathrm{O}_{2}$ ) with $P<0.05$.

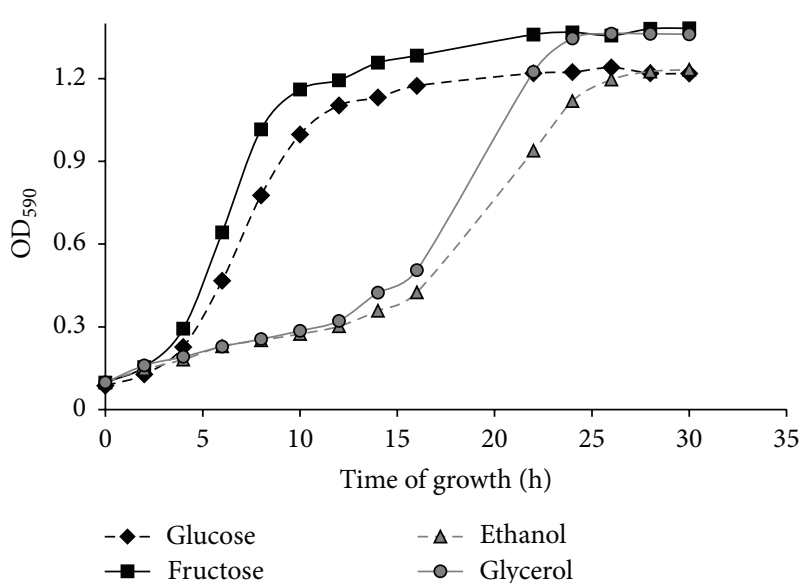

FIGURE 2: Growth curves of $S$. cerevisiae cultivated in a liquid medium with different carbon sources.

Figure 2, growth rates of the investigated cultures were rather similar during only the first $2 \mathrm{~h}$. After that, cells grown on fermentable monosaccharides entered the exponential phase. However, glycerol- and ethanol-cultivated cells did not finish growing in the lag phase over the next 10 hours, demonstrating their less adaptive ability to utilize available carbon sources than those grown on glucose or fructose. After entering the exponential phase, the growth characteristics of the four investigated cultures evaluated as the changes in optical density per hour $\left(\Delta \mathrm{OD}_{590} / \mathrm{h}\right)$ were $0.129,0.145$,
0.120 , and 0.087 , respectively. Optical density $\left(\mathrm{OD}_{590}\right)$ of the yeast suspension on $30 \mathrm{~h}$ of growth reflected the cell number in stationary culture was 1.22, 1.38, 1.36, and 1.23 for glucose-, fructose-, glycerol-, and ethanol-supplemented growth, respectively.

Therefore, the type of carbon source determines the growth rate of yeast culture and affects $\mathrm{H}_{2} \mathrm{O}_{2}$-induced hormetic phenotype.

3.3. $\mathrm{H}_{2} \mathrm{O}_{2}$-Induced Hormetic Response Depends on Metabolic Rate and Markers of Oxidative Stress in Yeast Cells. It is well documented that rate of aerobic growth is associated with metabolic activity and cellular redox state [17-19]. Figure 3 shows that the four studied types of yeast cells (glucose-, fructose-, ethanol-, and glycerol-grown) are characterized by different metabolic activities. The lowest parameter was found in glucose-grown cells. Yeast cultivated on fructose, ethanol, and glycerol demonstrates metabolic activity 2.2-, 3.3-, and 6.9-fold higher than that at glucose-supplemented growth, respectively. In accordance with that previously mentioned, the level of carbonyl groups in proteins (Figure 4), an indicator of oxidative stress [11,13, 20-22], was higher at growth on fructose, ethanol, and glycerol compared to glucose-grown yeast (2.3-, 1.7-, and 3.2-fold, resp.).

No marked difference between all the studied types of cells was found in their SOD activities (Figure 5). Unlike SOD, the activity of catalase tends to be higher in cells grown in the presence of nonfermentable carbon sources than fermentable monosaccharides (Figure 6), but, due to 


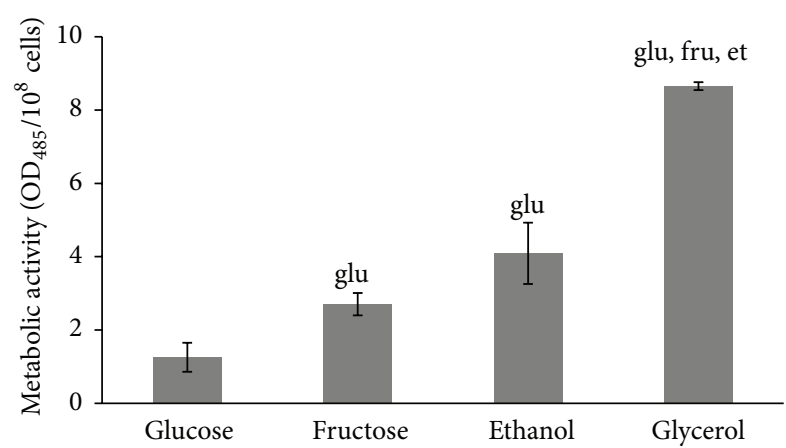

Figure 3: Metabolic activity of $S$. cerevisiae growing on different carbon sources. Results are shown as the mean \pm SEM $(n=4-5)$. Significantly different from respective values for cells growing on glu glucose, ${ }^{\text {fru }}$ fructose, and ${ }^{\text {et }}$ ethanol with $P<0.05$.

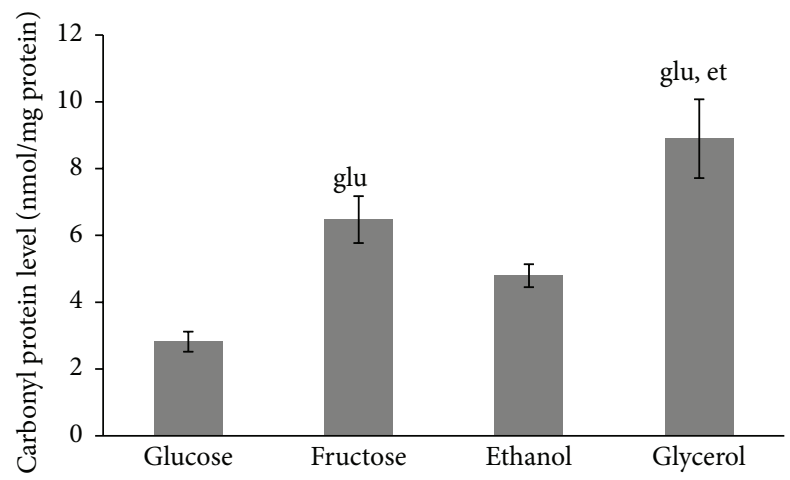

Figure 4: Carbonyl protein level of S. cerevisiae growing on different carbon sources. Results are shown as the mean \pm SEM $(n=3-4)$. Significantly different from respective values for cells growing on glu glucose and ${ }^{\text {et }}$ ethanol with $P<0.05$.

high variation in some trials, the parameter was significantly higher only in glycerol-grown cells (3.3-, 3.0-, and 1.8fold higher than those at glucose-, fructose-, and ethanolsupplemented growth, resp.). It is interesting to note that the total antioxidant capacity (Figure 7) demonstrated the opposite to catalase activity tendency (1.2-, 2.7-, and 2.4-fold lower in fructose-, ethanol-, and glycerol-grown cells than in glucose-grown cells, resp.).

\section{Discussion}

Hormesis is defined as a mild stress resulting in a life supporting beneficial effect of low doses of chemical, physical, or biological stressors that are unfavorable or lethal at their high doses $[2,3,23,24]$. This phenomenon is observed in a variety of organisms and usually limited to the $30-60 \%$ increase in a biological function [25]. Hydrogen peroxide was recently found to play a crucial role in the induction of hormesis and stress cross-resistance in yeast $[7,8,26]$. However, its effect depends very much on the concentrations used as well as biochemical and physiological peculiarities of the cells. For instance, fructose-grown yeast exposed to

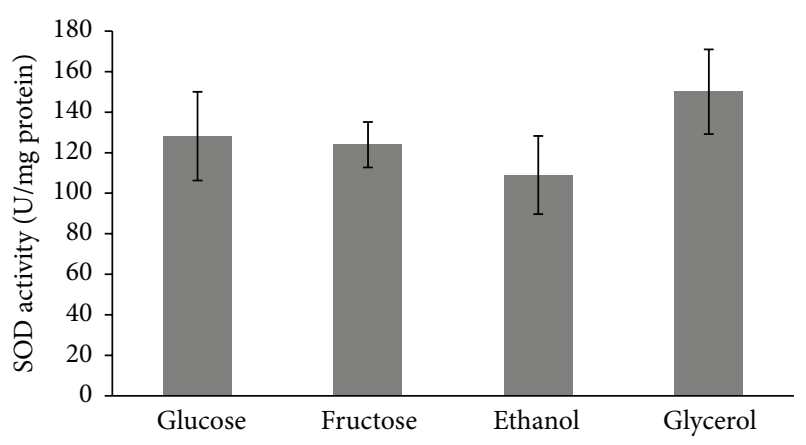

FIGURE 5: Activity of superoxide dismutase of $S$. cerevisiae growing on different carbon sources. Results are shown as the mean \pm SEM $(n=5-7)$

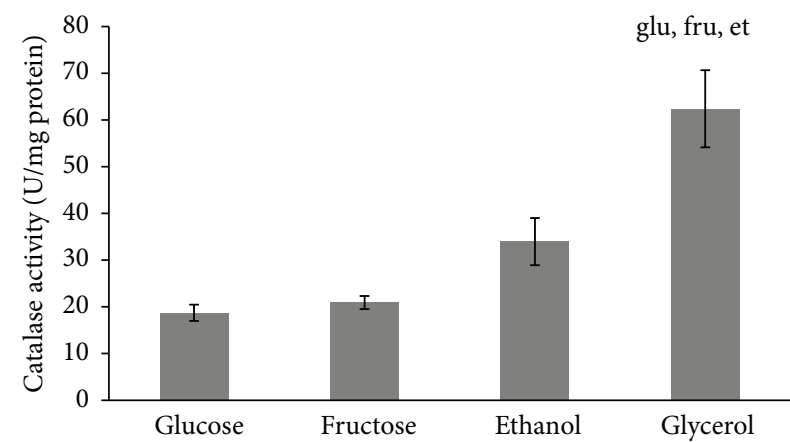

FIgURE 6: Activity of catalase of $S$. cerevisiae growing on different carbon sources. Results are shown as the mean \pm SEM $(n=4-5)$. * Significantly different from respective values for cells growing on glu glucose, ${ }^{\text {fru }}$ fructose, and ${ }^{\text {et }}$ ethanol with $P<0.05$.

low concentrations of $\mathrm{H}_{2} \mathrm{O}_{2}$ has been found to demonstrate higher reproductive ability than glucose-grown cells [16].

In order to expand our understanding of $S$. cerevisiae response to hydrogen peroxide we used a wide range of $\mathrm{H}_{2} \mathrm{O}_{2}$ concentrations (from 0.05 to $100 \mathrm{mM}$ ) and yeast cultivated on fermentable (glucose or fructose) and nonfermentable (glycerol or ethanol) carbon sources. All the investigated cell types demonstrated the biphasic dose-response relationship for effects of hydrogen peroxide on yeast reproductive ability, but the shape of hormetic curves was different (Figure 1). Both the studied types of cells cultivated on fermentable monosaccharides (glucose and fructose) demonstrated the sharp peak hormetic response but at different concentrations of hydrogen peroxide $\left(0.15 \mathrm{mM} \mathrm{H}_{2} \mathrm{O}_{2}\right.$ and $7.5 \mathrm{mM} \mathrm{H}_{2} \mathrm{O}_{2}$, resp.). Similarly to yeast grown in the presence of glucose, glycerol-grown cells have shown the hormetic response at low concentrations of hydrogen peroxide $(0.05-0.15 \mathrm{mM}$ $\mathrm{H}_{2} \mathrm{O}_{2}$ ). In contrast, hormetic response of ethanol-grown yeast was observed at a wide range of hydrogen peroxide concentrations (0.05-10.0 $\left.\mathrm{mM} \mathrm{H}_{2} \mathrm{O}_{2}\right)$.

Different metabolism of the four carbon sources used in this study underlies various yeast hormetic responses to hydrogen peroxide. It is well known from either in vitro or in vivo studies that fructose is more potent glycoxidation agent than glucose and therefore capable of producing greater 


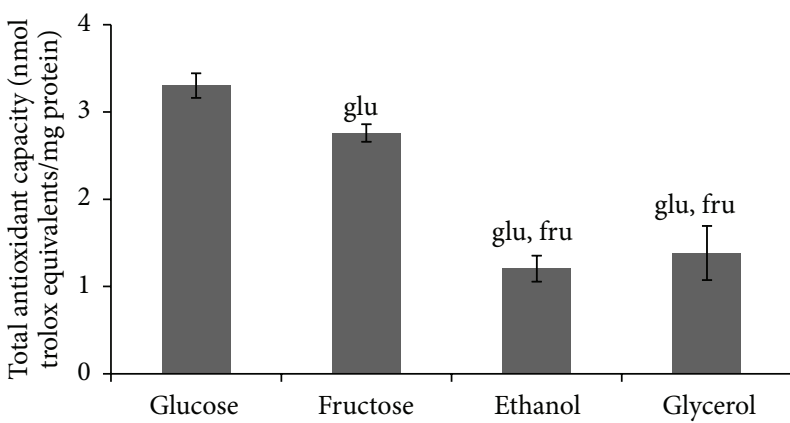

FIGURE 7: Total antioxidant capacity of $S$. cerevisiae growing on different carbon sources. Results are shown as the mean \pm SEM $(n=6-10)$. Significantly different from respective values for cells growing on ${ }^{\text {glu }}$ glucose and ${ }^{\text {fru }}$ fructose with $P<0.05$.

amounts of reactive intermediates like reactive carbonyl (RCS) and oxygen species (ROS) [27-30]. Recently we found a significantly higher ROS level ( 2.0-fold) in fructosegrown yeast than that in glucose-grown yeast and therefore suggested that fructose provoked a mild oxidative stress that stimulated cellular defensive mechanisms, including SOD and catalase [16,31]. This resulted in the acquisition of cellular resistance to lethal challenges and explained the higher survival of fructose-grown yeast than glucose-grown yeast under shock induced by high concentrations of $\mathrm{H}_{2} \mathrm{O}_{2}$ [16]. The findings of the present study are consistent with our previous suggestions and demonstrate that fructose-grown cells are more resistant to hydrogen peroxide than glucosegrown cells, and the peak hormetic responses in the first case are shifted to a higher concentration of $\mathrm{H}_{2} \mathrm{O}_{2}$.

Nonfermentable substrates like ethanol can provide yeast with energy produced via aerobic respiration, and leakage of electrons from the respiratory chain may lead to high ROS generation and induction of oxidative stress [20, 3234]. Chronic oxidative stress and stimulation of defensive enzymes in yeast growing on ethanol can explain a broad peak hormetic response to hydrogen peroxide. Lower resistance to $\mathrm{H}_{2} \mathrm{O}_{2}$ of glycerol-grown yeast demonstrating the hormetic response at low concentrations of oxidant as compared to cells cultivated in the presence of ethanol may be a result of specificity of glycerol and ethanol metabolism in the yeast. Although both substrates need active respiration, that is, operation of the electron transport chain, they are metabolized in different ways. For example, ethanol is directly oxidized to acetyl-CoA and enters the citric acid cycle [35]. Glycerol is phosphorylated and further reduced to give dihydroxyacetone phosphate. Further, it can be metabolized either by gluconeogenesis or by glycolysis and the citric acid cycle [36]. Thus, yeast utilizing ethanol produces more ROS than yeast growing on fermentable substrates [20], and therefore ethanol provokes a mild oxidative stress and yeast tolerance to a wide range of $\mathrm{H}_{2} \mathrm{O}_{2}$ concentrations. Thus preliminary oxidative stress as a result of yeast growth on certain carbon sources plays an important role in the acquisition of cellular resistance to following severe challenge as well as $\mathrm{H}_{2} \mathrm{O}_{2}$-induced hormetic response in yeast.
Different rates of yeast growth on the four carbon sources (Figure 2) and metabolic activities of the four studied cell types (Figure 3) seem to be an important precondition for various hormetic responses of $S$. cerevisiae to hydrogen peroxide (Figure 1). As one explanation, the above-mentioned different phenotypes are associated with various intensities of oxidative stress in yeast grown in the presence of glucose, fructose, ethanol, and glycerol. The above suggestions are consistent with the data showing the level of oxidative stress markers (Figures 4 and 6).

In living organisms, external factors can cause oxidative stress with different intensities. This has been put on the basis of modern classification of oxidative stress [3,23]. Recent comparative analysis of glucose and fructose vital effects on yeast clearly revealed that yeast grown on fructose had higher metabolic activity and levels of carbonyl groups in proteins as well as other markers of oxidative stress [28]. It is also well known that yeast utilizing nonfermentable substrates like ethanol and glycerol produces more ROS than yeast growing on fermentable carbon sources [20], and therefore the intensity of oxidative stress is higher in the case of cell cultivation in the presence of ethanol and glycerol than glucose and fructose. In accordance with the previous findings and our suggestions above on different intensity of oxidative stress in the four studied cell types as a precondition of their various hormetic responses to hydrogen peroxide, the correlation analysis of the relationship between metabolic activity (Figure 3), level of oxidized proteins (Figure 4), and activity of catalase (Figure 6) gives a strong positive correlation between the parameters (Figures $8(\mathrm{a}), 8(\mathrm{~b})$ ), and $8(\mathrm{c})$ ).

It should be noted that the primary antioxidant enzymes, SOD and catalase, were usually found to demonstrate a strong relationship [11, 16]; however in the present study the enzymes showed different behaviors. Unlike catalase, activity of which was higher in yeast grown on nonfermentable carbon sources (Figure 6), no substantive differences were observed for the effect of glucose, fructose, ethanol, and glycerol on SOD activity (Figure 5).

Surprisingly, when the total antioxidant capacity data were plotted against catalase activity, the dependence demonstrated a complicated pattern, negative correlation (Figure 8(d)). It has been reported that total antioxidant activity of S. cerevisiae strongly depended on the thiol content, depletion of which led to decrease of the total antioxidant capacity [37]. We suggest that under conditions of this study catalase is an important determinant of yeast protection against oxidative damage during aerobic growth, with the four substrates used.

\section{Conclusion}

In general, our data and correlation analysis suggest that high rate of metabolism in yeast grown on certain carbon sources leads to oxidative stress, since the intracellular level of carbonyl proteins is increased in these cases. Enhanced catalase activity also reveals oxidative stress development; however this stress is rather mild, whereas severe oxidative stress inactivates antioxidant enzymes mainly through oxidation of their active centers or carbonylation of amino acids 


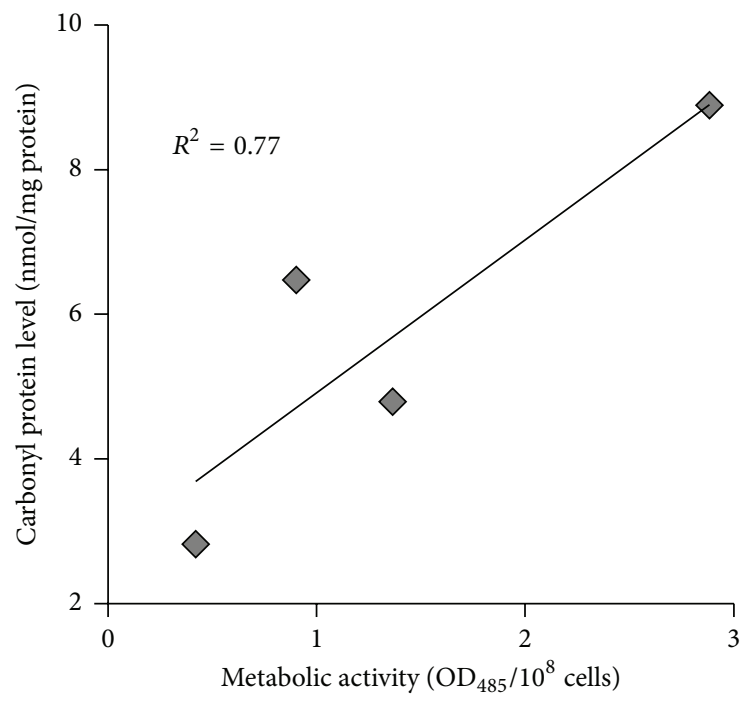

(a)

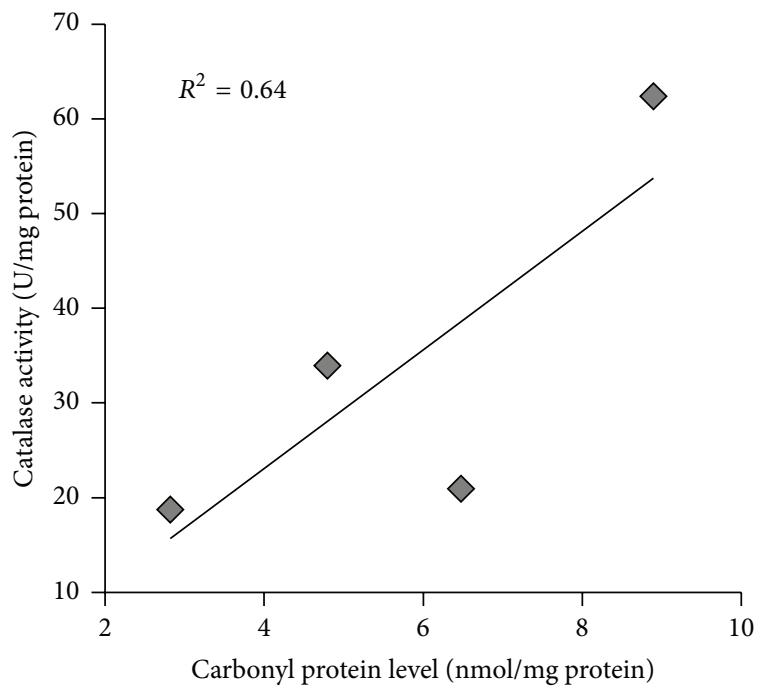

(c)

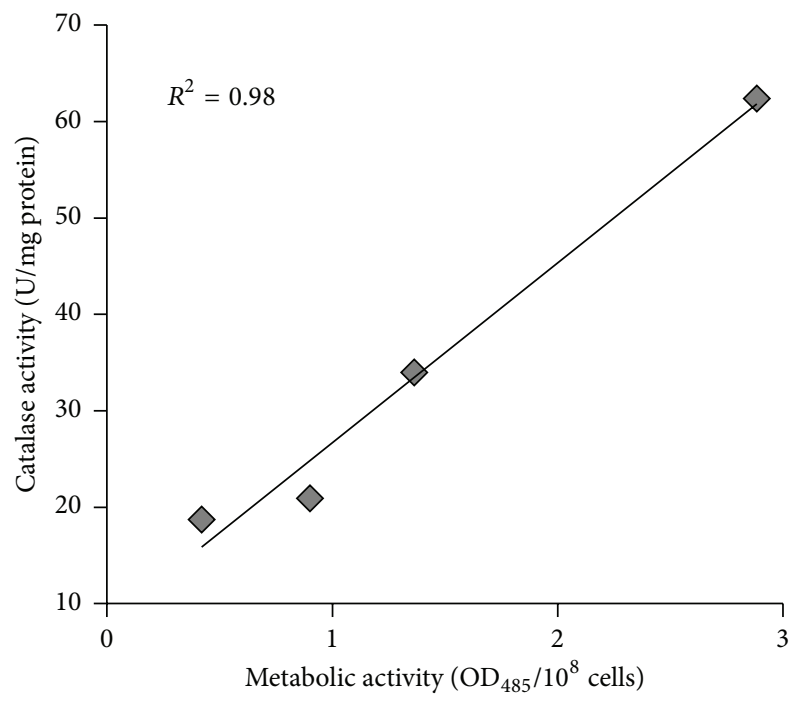

(b)

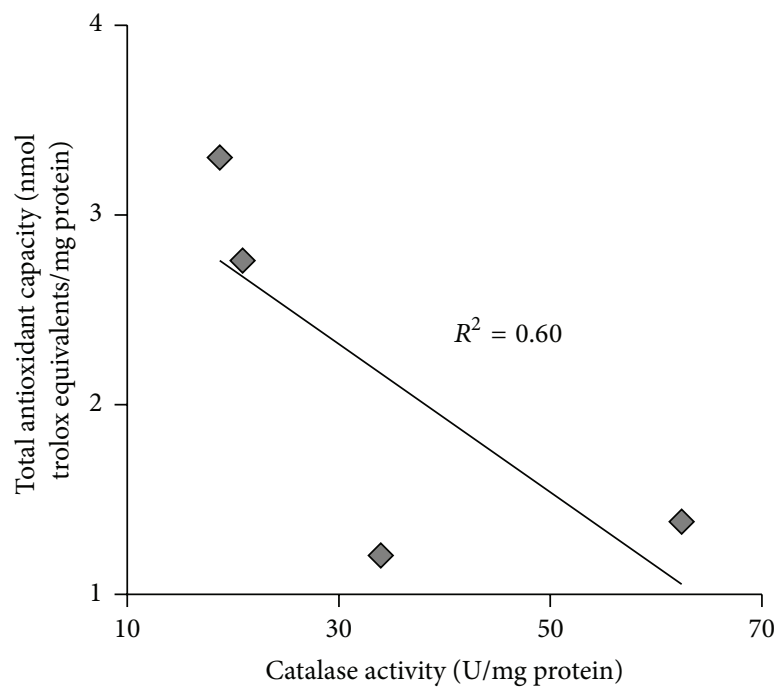

(d)

Figure 8: Correlation analysis of data obtained with S. cerevisiae growing on different carbon sources. Correlating between (a) carbonyl protein levels and metabolic activities; (b) catalase activities and metabolic activities; (c) catalase activities and carbonyl protein levels; and (d) total antioxidant capacities and catalase activities.

residues $[16,38,39]$. In turn, preliminary mild oxidative stress is an important precondition of the acquisition of cellular resistance to following severe oxidative stress as well as $\mathrm{H}_{2} \mathrm{O}_{2}$ induced hormetic response in yeast.

\section{Conflict of Interests}

The authors declare that there is no conflict of interests regarding the publication of this paper.

\section{Acknowledgment}

The authors are grateful to Professor Inoue for providing the yeast strain.

\section{References}

[1] E. J. Calabrese, "Hormesis: why it is important to toxicology and toxicologists," Environmental Toxicology and Chemistry, vol. 27, no. 7, pp. 1451-1474, 2008.

[2] I. Martins, L. Galluzzi, and G. Kroemer, "Hormesis, cell death and aging," Aging, vol. 3, no. 9, pp. 821-828, 2011.

[3] V. I. Lushchak, "Dissection of the hormetic curve: analysis of components and mechanisms," Dose-Response, vol. 12, no. 3, pp. 466-479, 2014.

[4] V. Calabrese, C. Cornelius, A. T. Dinkova-Kostova et al., "Cellular stress responses, hormetic phytochemicals and vitagenes in aging and longevity," Biochimica et Biophysica Acta (BBA)Molecular Basis of Disease, vol. 1822, no. 5, pp. 753-783, 2012.

[5] D. B. Berry and A. P. Gasch, "Stress-activated genomic expression changes serve a preparative role for impending stress in 
yeast," Molecular Biology of the Cell, vol. 19, no. 11, pp. 4580-4587, 2008.

[6] I. Milisav, B. Poljsak, and D. Šuput, "Adaptive response, evidence of cross-resistance and its potential clinical use," International Journal of Molecular Sciences, vol. 13, no. 9, pp. 10771-10806, 2012.

[7] H. M. Semchyshyn, "Hormetic concentrations of hydrogen peroxide but not ethanol induce cross-adaptation to different stresses in budding yeast," International Journal of Microbiology, vol. 2014, Article ID 485792, 5 pages, 2014.

[8] P. Ludovico and W. C. Burhans, "Reactive oxygen species, ageing and the hormesis police," FEMS Yeast Research, vol. 14, no. 1, pp. 33-39, 2014.

[9] E. Cabiscol, E. Piulats, P. Echave, E. Herrero, and J. Ros, "Oxidative stress promotes specific protein damage in Saccharomyces cerevisiae," The Journal of Biological Chemistry, vol. 275, no. 35, pp. 27393-27398, 2000.

[10] Y. Inoue, T. Matsuda, K.-I. Sugiyama, S. Izawa, and A. Kimura, "Genetic analysis of glutathione peroxidase in oxidative stress response of Saccharomyces cerevisiae," The Journal of Biological Chemistry, vol. 274, no. 38, pp. 27002-27009, 1999.

[11] M. Bayliak, H. Semchyshyn, and V. Lushchak, "Effect of hydrogen peroxide on antioxidant enzyme activities in Saccharomyces cerevisiae is strain-specific," Biochemistry, vol. 71, no. 9, pp. 10131020, 2006

[12] A. Conconi, P. Jager-Vottero, X. Zhang, B. C. Beard, and M. J. Smerdon, "Mitotic viability and metabolic competence in UVirradiated yeast cells," Mutation Research/DNA Repair, vol. 459, no. 1, pp. 55-64, 2000.

[13] R. L. Levine, D. Garland, C. N. Oliver et al., "Determination of carbonyl content in oxidatively modified proteins," Methods in Enzymology, vol. 186, pp. 464-478, 1990.

[14] O. Erel, "A novel automated direct measurement method for total antioxidant capacity using a new generation, more stable ABTS radical cation," Clinical Biochemistry, vol. 37, no. 4, pp. 277-285, 2004.

[15] M. M. Bradford, "A rapid and sensitive method for the quantitation of microgram quantities of protein utilizing the principle of protein-dye binding," Analytical Biochemistry, vol. 72, no. 1-2, pp. $248-254,1976$.

[16] H. M. Semchyshyn and L. M. Lozinska, "Fructose protects baker's yeast against peroxide stress: potential role of catalase and superoxide dismutase," FEMS Yeast Research, vol. 12, no. 7, pp. 761-773, 2012.

[17] M. I. González-Siso, A. García-Leiro, N. Tarrío, and M. E. Cerdán, "Sugar metabolism, redox balance and oxidative stress response in the respiratory yeast Kluyveromyces lactis," Microbial Cell Factories, vol. 8, article 46, 2009.

[18] F. Magherini, A. Carpentieri, A. Amoresano et al., "Different carbon sources affect lifespan and protein redox state during Saccharomyces cerevisiae chronological ageing," Cellular and Molecular Life Sciences, vol. 66, no. 5, pp. 933-947, 2009.

[19] J. M. Van Raamsdonk, Y. Meng, D. Camp et al., "Decreased energy metabolism extends life span in Caenorhabditis elegans without reducing oxidative damage," Genetics, vol. 185, no. 2, pp. 559-571, 2010.

[20] V. Costa and P. Moradas-Ferreira, "Oxidative stress and signal transduction in Saccharomyces cerevisiae: insights into ageing, apoptosis and diseases," Molecular Aspects of Medicine, vol. 22, no. 4-5, pp. 217-246, 2001.
[21] V. I. Lushchak, "Free radical oxidation of proteins and its relationship with functional state of organisms," Biochemistry, vol. 72, no. 8, pp. 809-827, 2007.

[22] V. I. Lushchak, “Oxidative stress in yeast," Biochemistry, vol. 75, no. 3, pp. 281-296, 2010.

[23] V. I. Lushchak, "Classification of oxidative stress based on its intensity," EXCLI Journal, vol. 13, pp. 922-937, 2014.

[24] E. J. Calabrese, "Hormesis within a mechanistic context," Homeopathy, vol. 104, no. 2, pp. 90-96, 2015.

[25] V. Calabrese, C. Cornelius, S. Cuzzocrea, I. Iavicoli, E. Rizzarelli, and E. J. Calabrese, "Hormesis, cellular stress response and vitagenes as critical determinants in aging and longevity," Molecular Aspects of Medicine, vol. 32, no. 4-6, pp. 279-304, 2011.

[26] A. Mesquita, M. Weinberger, A. Silva et al., "Caloric restriction or catalase inactivation extends yeast chronological lifespan by inducing $\mathrm{H}_{2} \mathrm{O}_{2}$ and superoxide dismutase activity," Proceedings of the National Academy of Sciences of the United States of America, vol. 107, no. 34, pp. 15123-15128, 2010.

[27] I. Spasojević, A. Bajić, K. Jovanović, M. Spasić, and P. Andjus, "Protective role of fructose in the metabolism of astroglial C6 cells exposed to hydrogen peroxide," Carbohydrate Research, vol. 344, no. 13, pp. 1676-1681, 2009.

[28] H. M. Semchyshyn, L. M. Lozinska, J. Miedzobrodzki, and V. I. Lushchak, "Fructose and glucose differentially affect aging and carbonyl/oxidative stress parameters in Saccharomyces cerevisiae cells," Carbohydrate Research, vol. 346, no. 7, pp. 933938, 2011

[29] M. Sakai, M. Oimomi, and M. Kasuga, "Experimental studies on the role of fructose in the development of diabetic complications," Kobe Journal of Medical Sciences, vol. 48, no. 5-6, pp. 125-136, 2002.

[30] H. M. Semchyshyn, J. Miedzobrodzki, M. M. Bayliak, L. M. Lozinska, and B. V. Homza, "Fructose compared with glucose is more a potent glycoxidation agent in vitro, but not under carbohydrate-induced stress in vivo: potential role of antioxidant and antiglycation enzymes," Carbohydrate Research, vol. 384, pp. 61-69, 2014.

[31] H. M. Semchyshyn, "Fructation in vivo: detrimental and protective effects of fructose," BioMed Research International, vol. 2013, Article ID 343914, 9 pages, 2013.

[32] V. I. Lushchak and D. V. Gospodaryov, "Catalases protect cellular proteins from oxidative modification in Saccharomyces cerevisiae," Cell Biology International, vol. 29, no. 3, pp. 187-192, 2005.

[33] D. Stanley, A. Bandara, S. Fraser, P. J. Chambers, and G. A. Stanley, "The ethanol stress response and ethanol tolerance of Saccharomyces cerevisiae," Journal of Applied Microbiology, vol. 109, no. 1, pp. 13-24, 2010.

[34] I. Bleoanca, A. R. C. Silva, C. Pimentel, C. Rodrigues-Pousada, and R. D. A. Menezes, "Relationship between ethanol and oxidative stress in laboratory and brewing yeast strains," Journal of Bioscience and Bioengineering, vol. 116, no. 6, pp. 697-705, 2013.

[35] F. Faria-Oliveira, S. Puga, and C. Ferreira, "Yeast: world's finest chef," in Food Industry, I. Muzzalupo, Ed., chapter 23, pp. 519547, InTech, Rijeka, Croatia, 2013.

[36] A.-K. Påhlman, K. Granath, R. Ansell, S. Hohmann, and L. Adler, "The yeast glycerol 3-phosphatases Gpplp and Gpp2p are required for glycerol biosynthesis and differentially involved in the cellular responses to osmotic, anaerobic, and oxidative 
stress," The Journal of Biological Chemistry, vol. 276, no. 5, pp. 3555-3563, 2001.

[37] A. Balcerczyk, A. Grzelak, A. Janaszewska et al., "Thiols as major determinants of the total antioxidant capacity, BioFactors, vol. 17, no. 1-4, pp. 75-82, 2003.

[38] S. Y. Kim, O. J. Kwon, and J.-W. Park, "Inactivation of catalase and superoxide dismutase by singlet oxygen derived from photoactivated dye," Biochimie, vol. 83, no. 5, pp. 437-444, 2001.

[39] V. M. V. Costa, M. A. Amorim, A. Quintanilha, and P. MoradasFerreira, "Hydrogen peroxide-induced carbonylation of key metabolic enzymes in Saccharomyces cerevisiae: the involvement of the oxidative stress response regulators Yapl and Skn7," Free Radical Biology and Medicine, vol. 33, no. 11, pp. 1507-1515, 2002. 

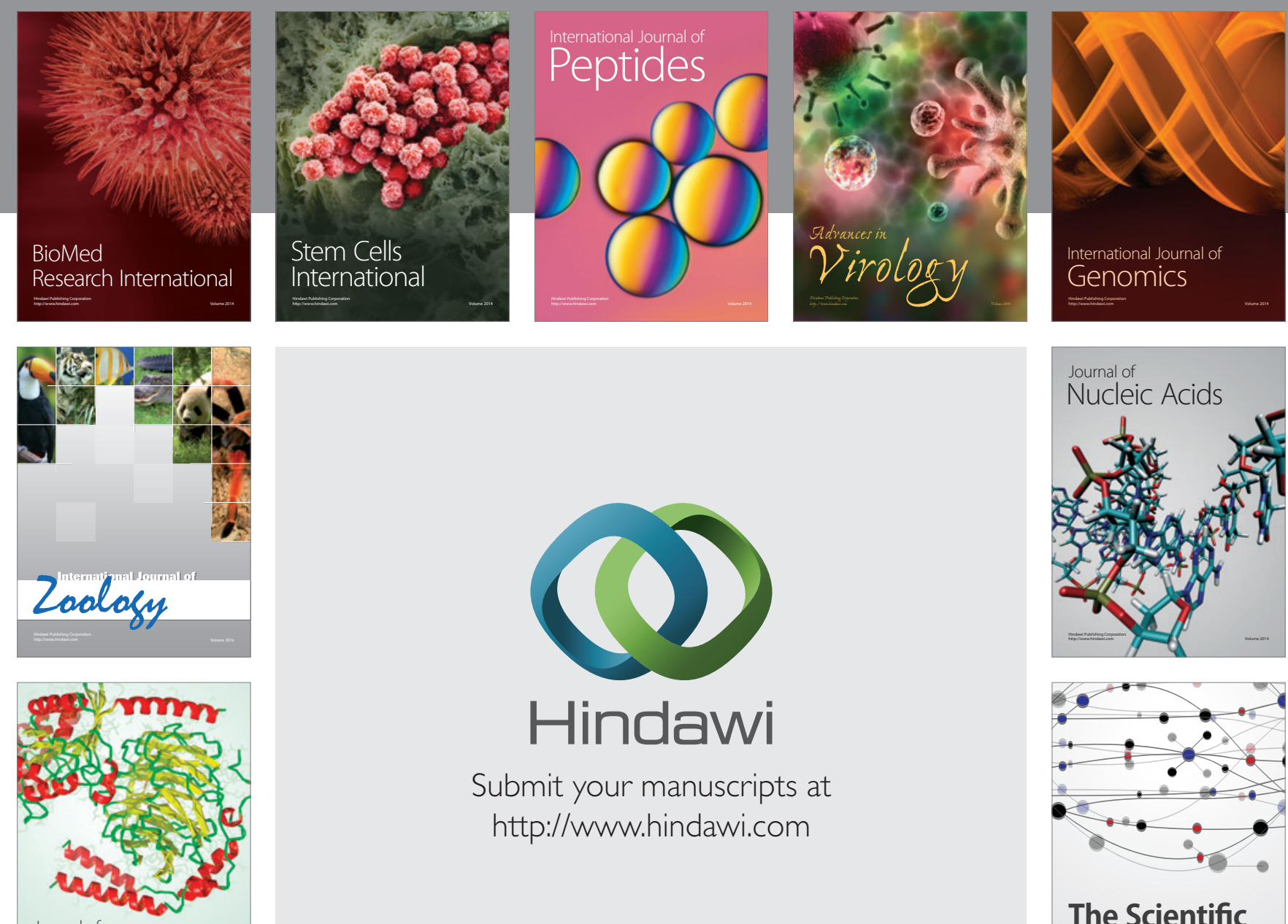

Submit your manuscripts at

http://www.hindawi.com

Journal of
Signal Transduction
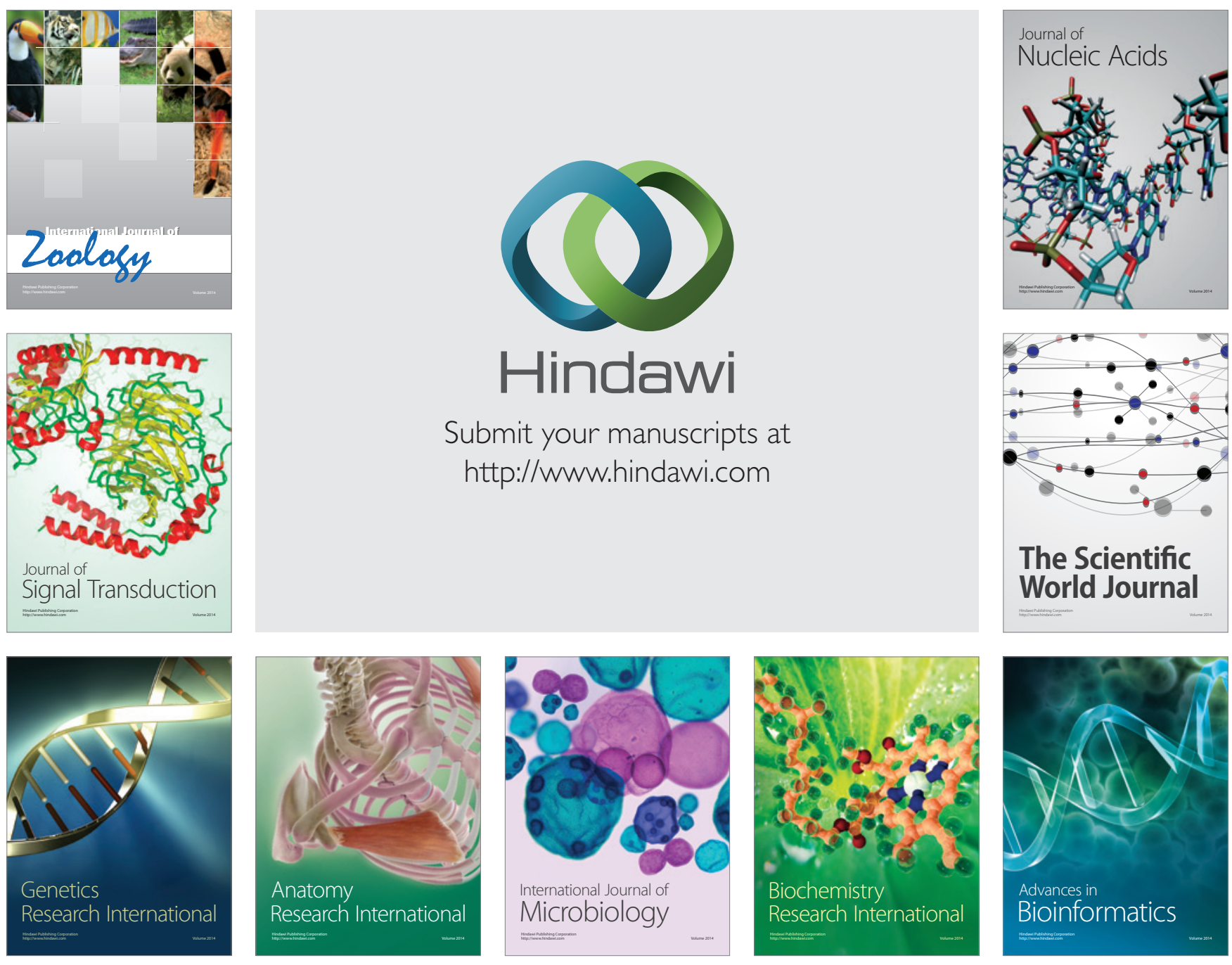

The Scientific World Journal
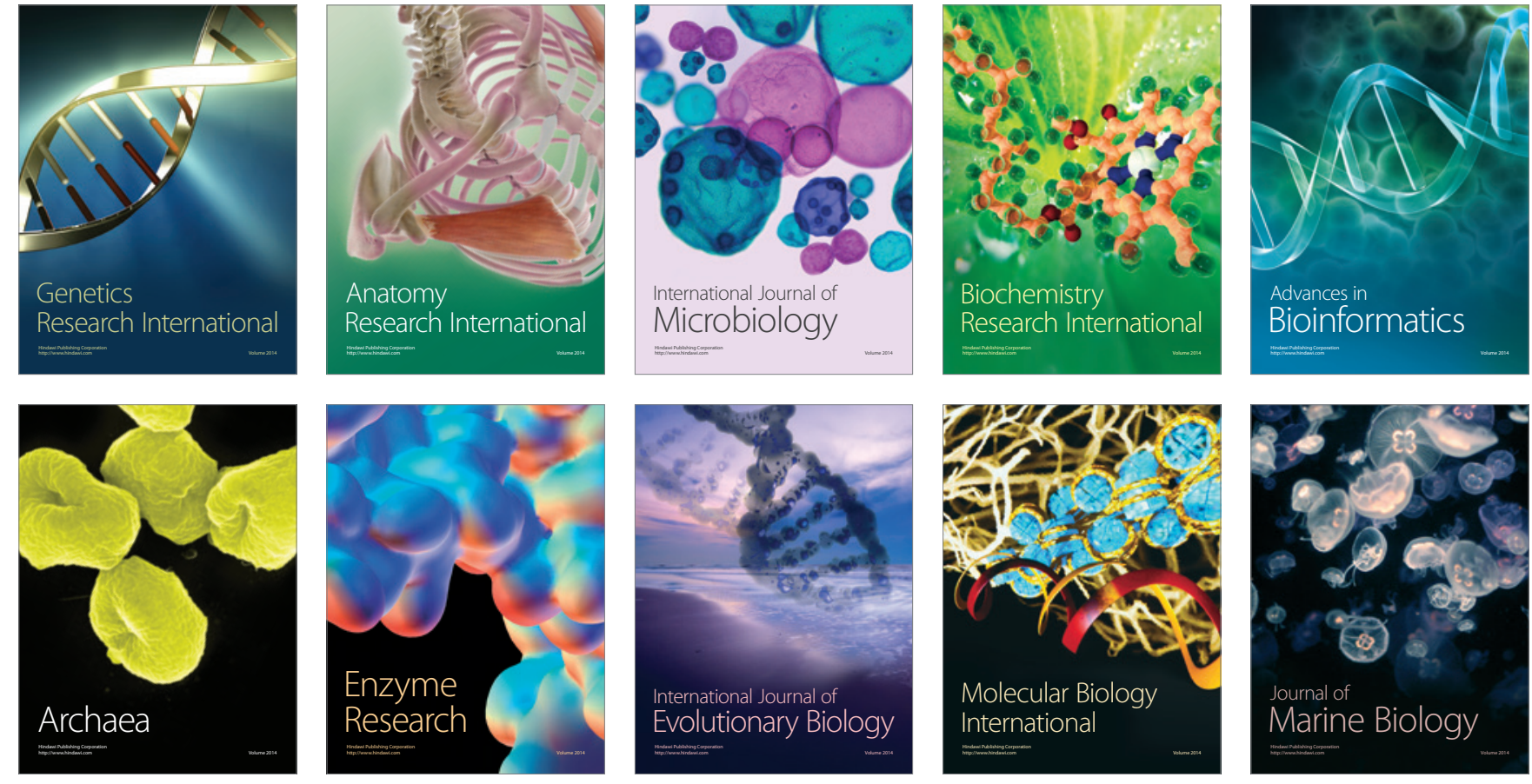